\title{
The Cyclic Feeding Regime Induces Decaying Age-Dependent Oxidative Stress and Regulates the Cell Chain of the Immunity
}

\author{
Anatoly I. Bozhkov*, Yuriy V. Nikitchenko, Katerina N. Lebed', Olena S. Linkevych, \\ Natalia I. Kurguzova, Olena M. Klimova, Mohammad A. Y. Al Begai, \\ Ali M. M. Al-Bahadly, Mohammad M. A. Alsardia \\ Research Institute of Biology, V.N. Karazin Kharkov National University, Kharkov, Ukraine \\ Email: bozhkov@univer.kharkov.ua
}

How to cite this paper: Bozhkov, A.I., Nikitchenko, Y.V., Lebed', K.N., Linkevych, O.S., Kurguzova, N.I., Klimova, O.M., Al Begai, M.A.Y., Al-Bahadly, A.M.M. and Alsardia, M.M.A. (2016) The Cyclic Feeding Regime Induces Decaying Age-Dependent Oxidative Stress and Regulates the Cell Chain of the Immunity. Advances in Aging Research, 5, 151-165.

http://dx.doi.org/10.4236/aar.2016.56015

Received: September 20, 2016

Accepted: November 7, 2016

Published: November 10, 2016

Copyright $\odot 2016$ by authors and Scientific Research Publishing Inc. This work is licensed under the Creative Commons Attribution International License (CC BY 4.0).

http://creativecommons.org/licenses/by/4.0/

\begin{abstract}
We developed an experimental model of a cyclic feeding regime (CFR) that increased a lifespan in rats. The manifestations of oxidative stress and their interrelation with parameters of cell immunity were assessed in rats at CFR. It is shown that changes of body mass, liver mass and indexes of pro/antioxidant system after periods of starving-ad libitum nutrition at CFR diet in old animals were less pronounced than in young animals. The body mass loss of $30 \%$ in 14 days was accompanied by oxidative stress. Indexes of phagocytosis did not change, but activity of oxidase system of neutrophil was increased in 2 times. The response of metabolic and physiological systems on repeat starving-ad libitum nutrition cycles differs from the response to the initial cycle of CFR. This is interpreted as a change of adaptation strategy and the effect of metabolic memory, which influences the choice of organism strategy of adaptation for subsequent starving. The dynamics of change of the studied indexes in response to CFR was age-dependent. It was supposed that different answer to CFR in young and old animals is determined by the different amount of carbon and fat depots in young and old animals.
\end{abstract}

\section{Keywords}

Aging, Oxidative Stress, Cyclic Feeding Regime, Primary Immunity, Pro-Oxidant System

\section{Introduction}

The biological model of the calorie restriction (CR), which was firstly proposed by McCain in 1935 is widely used in current experimental gerontology [1]-[3]. According 
to a number of professionals it is one of the most successful models of experimental ways to increase life span [2]-[5]. In this model we have been received extremely important and interesting results on the role of free radical processes in the aging mechanisms [6], the role of apoptosis, calorie restricted diets [7], and others. At the same time, as any model the CR model has limitations and drawbacks. It "works" in the case if only young animals ( $1-2$ months) are transferred to CR.

We have developed another version of the experimental model of lifespan increasethe cyclic feeding regime (CFR) [8]. This model is of interest in several aspects: 1) it can be applied not only for young, but also to adult animals; 2) it allows to explore the features and characteristics of metabolic-epigenetic memory, since it is easy to determine the reproducibility of the response after repeated cycles of loss-renovation of body mass; 3) in future it can be extended to man, in contrast to the CR. After 3 cycles of CFR the mean lifespan of rats is just the same as in animals received CR diet all their life [8] [9]. Since $30 \%$ of mass loss, which occurs at the CFR and induces stress reaction, it was of interest to investigate the response of organism after 2 cycles of consecutive body mass losses-renovation in young and old animals.

In assessment of the response of organism it was evaluated some indicators of prooxidant-antioxidant system (lipid hydroperoxide amount, aconitase and glutathione peroxidase activity) and indicators of cellular immunity (phagocytic index, phagocytic number and index of completion of phagocytosis).

The activation of prooxidant system and inhibition of antioxidant system are known to be the most expressive reactions of organism to stress. Action of free radicals is dual: increased amount of free radicals, on the one hand, can induce pathological processes and, on the other hand, can activate the system of adaptation by immune system activation. In the present study the relationship between indexes of prooxidant-antioxidant system and the indexes of phagocytic activity of neutrophils was determined in young and old animals maintained at the cycling feeding regime.

\section{Materials and Methods}

The research was conducted using 3 and 19 months old males of Wistar rats. All experiments on rats were performed in accordance with the European Convention for the protection of vertebrate animals used for experimental and other scientific purposes. Three and nineteen months old rats were divided into the control and experimental groups: control animals were maintained on standard feeding regime, and experimental groups were fed according to the CFR. CFR is a feeding regime on which experimental rats lost up to $30 \%$ of their body mass during 14 days. After that the feeding regime was changed in order to recover the body mass in 14 days. Then animals were kept under standard conditions in a vivarium for 30 days (rehabilitation). All these stages comprised one cycle of the feeding regime. The CFR scheme is described in detail [8].

Experimental animals were regularly weighed at the same time before feeding.

Before killing, animals were anesthetized. Blood was collected into dry centrifuge tubes, incubated $30 \mathrm{~min}$ at $20^{\circ} \mathrm{C}$, and centrifuged for $15 \mathrm{~min}$ at $1500 \mathrm{~g}$ and was deter- 
mined activity of glutathionperoxidase (GPx) (EC 1.11.1.9) as described [10].

Phagocytic activity of neutrophils was assessed by the absorption and elimination of microbial cells Saccharomyces cerevisiae by neutrophilic granulocytes (NG) using light microscopy method [11].

Nitro blue tetrazolium (NBT)-test. The method is based on the ability of neutrophils to absorb the nitro blue tetrazolium and its recovery in granules of insoluble diformazan. Diformazan in cells is visible in microscope granules of blue color that are produced under influence of superoxide anion, which is produced in NADFH oxidase reaction. This reaction initiates the process of phagocyte stimulation. NBT test characterizes oxygen-dependent anti-infective systems of phagocyte.

To estimate enzyme activity of granulocytic neutrophils we assessed different classes of stained cells in 100 cells stained by difarmasan, using light microscopy method under magnification of $10 \times 90$ [12].

The liver was perfused by cold physiological solution $\left(4^{\circ} \mathrm{C}\right)$, then liver was weighted and relative liver mass in percent to body mass was calculated. The mitochondria were obtained by differential centrifugation [13].

In the mitochondria fraction the amount of lipid hydroxide was determined by the method of Ohkawa et al. [14], activity of glutathionperoxidase (GPx) (EC 1.11.1.9) as described [10]. Aconitate hydratase activity (aconitase, EC 4.2.1.3., AG) was determined as described [15].

All experiments were repeated not less than 5 times; in each experimental group there were not less than five animals. The results were statistically processed using nonparametric (the Wilcoxon-Mann-Whitney test) and parametric (Student's $t$-test) statistical methods [16]. The Statistica 6 software was applied. Results were considered as statistically significant at $p<0.05$.

\section{Results}

\subsection{Age-Related Changes in Body Mass on Two Consecutive Cycles of Feeding}

Transfer of 3 months old and 20 months old animals on the CFR for 14 days was accompanied by a loss of $33 \%$ and $26 \%$ of the body mass in the first cycle of body mass loss (Figure 1(a)). In the repeated cycle of CFR 3 months old animals lost $41 \%$ of its initial mass, and 20 months old lost the same-26\% (Figure 1(a)).

Further transfer of animals to ad libitum feeding for the next 14 days provided the increase of the body mass of 3 months old animals by $92 \%$, and 20 months old $-24 \%$ by mass (Figure 1(a)). After the second transfer of these animals to ad libitum feeding for the 14 days the mass of young animals increased only by $45 \%$, that is 2 times less than at the first cycle of restoration (Figure 1(a)).

Previously, it was shown, that after 3 consecutive CFR cycle in young animals body mass lagged as compared to control by $18 \%$, and old animals even exceeded in body mass the control group by $10 \%$ [8].

Consequently, the transfer of experimental animals at CFR was accompanied by: 1) 
the cyclical changes in body mass; 2) the amplitude of the body mass changes to a more extent has been expressed in 3 months old animals than for old animals; 3 ) if for young animals after CRF the body mass was significantly less than in the control group, for the old animals, on the contrary, it increased and remained at the constant level as compared to the control group.

Change in the body mass was accompanied by pronounced changes in liver mass. The relative liver mass in 3 months old rats in the first cycle decreased by $36 \%$, and in 20 months old rats-by $31 \%$. After the first cycle of the initial body mass recovery the body mass recovered to the initial mass in only 20 months old rats and to a lesser extent recovered in young (Figure $1(\mathrm{~b})$ ).

After the second cycle of body mass loss, the liver mass decreased by $46 \%$ in young and did not changed in old rats (Figure $1(\mathrm{~b})$ ).

The second cycle of restoration of body mass did not affect the relative liver mass in old animals and it was observed its restoration in 3-month-old animals.

It should be noted that with age the relative liver mass decreased [8], i.e. body mass increases faster than the mass of the liver during ontogenesis.

Consequently, the relative liver mass in young animals changed in a greater extent than in old animals. Such a pronounced change in liver mass was due to the metabolic reorganization of the liver with age.

\subsection{Indexes Pro-Antioxidant System in Young and Old Animals after Two Sequential Cycles of CFR}

The amount of lipid hydroperoxides (LOOHs) in the mitochondria of the liver of

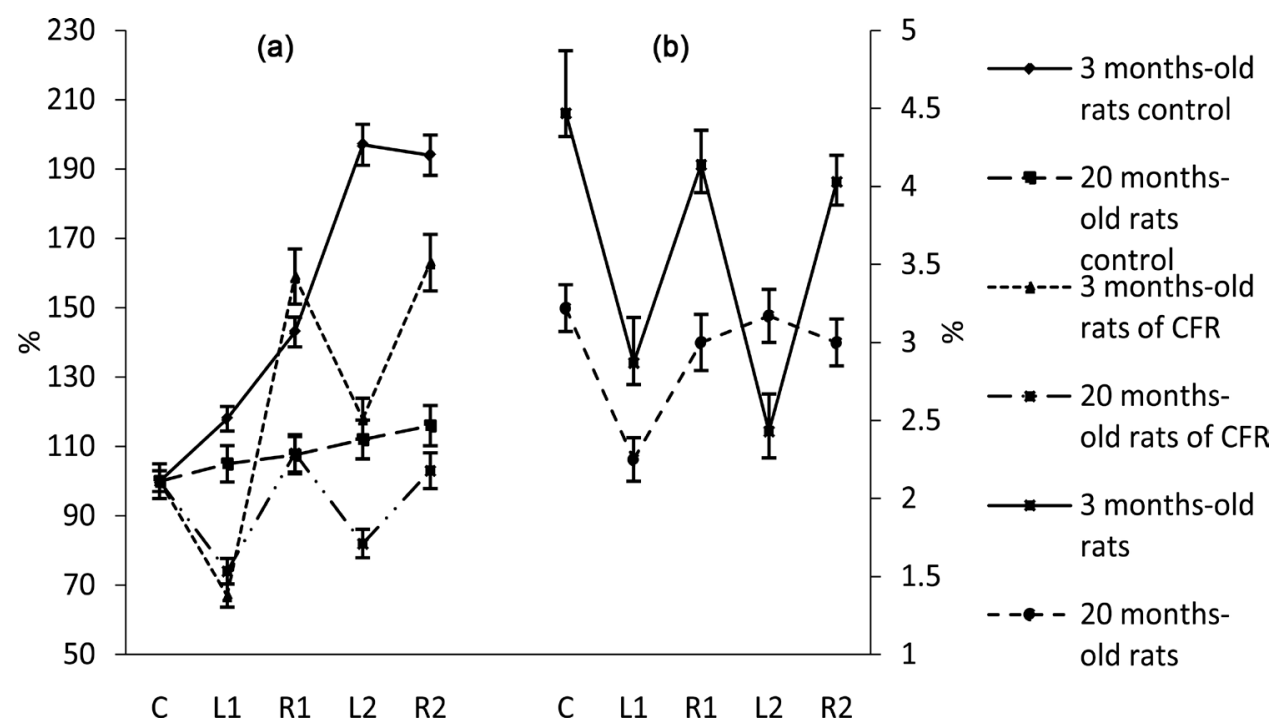

On the $\mathrm{x}$-axis: $\mathrm{C}$-control group; $\mathrm{L} 1-$ the loss of body mass in the first cycle of CFR; R1-the restoration of body mass in the first cycle and, L2 and R2, respectively, in the second CFR cycle. We present the average values of 5 - 10 repeats. $p \leq 0.05$ to compared with control group.

Figure 1. The dynamics of body mass in 3 and 20 months old rats of the control group and the group on the cyclic of the feeding regime (a) and the dynamics of changes in the relative liver mass (\% of body mass) in 3 and 20 months old rats at different stages of CFR (b). 
young animals has been increased by $105 \%$ on the first cycle of mass loss (Figure 2). At the same time, in old animals it was increased only by $69 \%$ compared to control (Figure 2(a), Figure 2(c)).

Transfer of animals to a normal feeding regime was accompanied by a decrease in the content of LOOH in the mitochondria of the liver, both in young and old animals (it reached the base control level) (Figure 2(a), Figure 2(c)).

The body mass loss during the second cycle of CFR was accompanied by a much smaller increase of the quantity of $\mathrm{LOOH}$ than in first CFR cycle, in liver mitochondria in young animals (50\% compared to the control level) and $\mathrm{LOOH}$ remained unchanged in old animals (Figure 2(a), Figure 2(c)). The quantity of LOOH in liver mitochondria
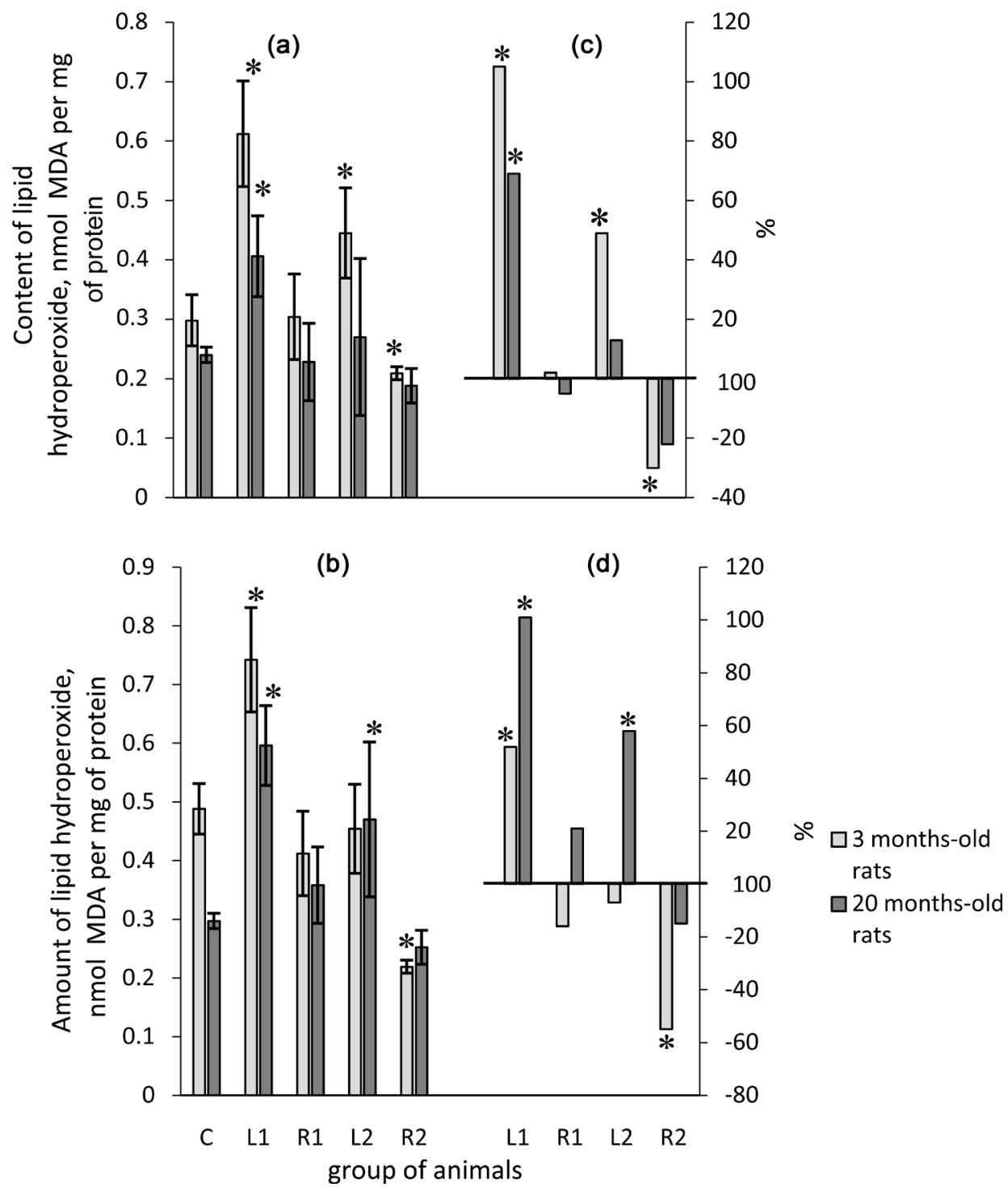

Figure 2. The contents of lipid hydroperoxide (nmol MDA) in themitochondria (a) and fraction of microsomes (b) in young ( 3 months old) and old (20 months old) animals. C, L1, R1, L2, and R2-animal groups as in Figure 1. Changing of these parameters is shown in percent to the control level in mitochondria (c) and microsomes (d). 
in 3 months old and 20 months old animals after the second cycle of body mass restoration was below its level in corresponding age control animal group (Figure 2(a), Figure 2(c)).

Consequently, the body mass loss and recovery revealed an increase of the amount of $\mathrm{LOOH}$ in liver mitochondria. Therefore, the first body mass loss was accompanied by a series of severe oxidative stress in young and less in old animals. The second cycle of mass loss caused a 2-fold less effect on LOOH in the mitochondria, both in young and old animals. Recovery of body mass in young and old animals in the second cycle CFR was not accompanied by decrease of the mitochondria $\mathrm{LOOH}$ to baseline, both in young and old animals.

As it is known, the of $\mathrm{LOOH}$ production in the liver is the membranes of the endoplasmic reticulum (microsomes). Dynamics of LOOH in microsomes at CFR was the same as in the mitochondria. At the same time it is revealed quantitative differences between age groups. The quantity of $\mathrm{LOOH}$ in microsomes of 3 months old rats in result of body mass loss in the first cycle increased by $52 \%$ compared with the control, and in 20 months old rats by $100 \%$ (Figure 2(b), Figure 2(d)). LOOH amount did not differ from the control level after mass recovery in the first cycle (Figure 2(b), Figure $2(c))$.

On the second mass loss cycle the amount of LOOH didn't change in microsomes of young rats and slightly increased in 20 months old rats. Meanwhile, after the second cycle of body mass recovery $\mathrm{LOOH}$ amount in microsomes of 3 months old rats was 56\% lower than compared to control, and for 20 months old rats it didn't differ from control age group level (Figure 2(b), Figure 2(d)). The oxidative stress induced by CFR, manifested in a significant increase of $\mathrm{LOOH}$ amount in the mitochondria and microsomes in the first cycle of mass loss. Further, in second CFR cycle LOOH changes were less expressed or were absent. It is believed that these changes in the pro-oxidant system lead to the "formation" of new $\mathrm{LOOH}$ level in mitochondria and microsomes.

It is known, that aconitase of mitochondria is the most vulnerable element of Krebs cycle. It is inhibited by active forms of oxygen and nitric oxide [17] [18] at oxygen and glucose starvation [19]. The aconitase activity of liver mitochondria under CFR was changed differently in young and old animals (Figure 3). At the first and second cycles of body mass loss the activity of aconitase decreased in 30\%, at body mass recovery aconitase activity increased, but after the first cycle of body mass recovery aconitase activity didn't reach control level. In the second cycle of body mass recovery, its activity decreased in $24 \%$ to compare with control level (Figure 3 ). The activity of mitochondrial aconitase in the liver of old rats didn't change under CFR.

As it is known, $\mathrm{LOOH}$ amount depends on influence of many factors and, in particular, on the activity of antioxidant enzymes. The glutathione peroxidase (GPx), as previously been shown to be among the most labile and important antioxidant enzymes [20].

Determination of GPx activity has shown that it varies greatly in response to the body mass loss and recovery, and in this particular case no correlation between GPx ac- 
tivity not correlate with LOOH amount.

The body mass loss in 3 months old rats in the first cycle was accompanied by increase in GPx activity in the liver mitochondria at $142 \%$, and in 20 months old rats only by $33 \%$ (Figure $4($ a), Figure $4(\mathrm{c})$ ).

After the body mass recovery the GPx activity in mitochondria was $33 \%$ higher in 3 months old rats, and $88 \%$ higher in 20 months old rats compared to the control. (Figure 4(a), Figure 4(c)).

In the second cycle of body mass loss GPx activity increased even greater extent than in the first cycle-at $251 \%$ in the young and $142 \%$ in old rats (Figure 4(a), Figure 4(c)).

After the second cycle of body mass recovery GPx activity in liver mitochondria remained almost as high both in young and old animals (234\% and 97\%, respectively, compared to the control) (Figure 4(a), Figure 4(c)).

Consequently, between the change in the activity of the GPx and the amount of $\mathrm{LOOH}$ in the mitochondria at the loss-recovery of body mass, as a result of CFR, there is no correlation. The GPx induction exceeds the increase of LOOH amount i.e. it remains on the high level even after CFR cycle completion.

It is known that there are several different classes of GPx, which are distinguished by the localization, activity and substrate specificity [21]. In the next series of experiments GPx activity in the blood serum was determined.

The second mass loss cycle is accompanied by GPx activity increase in the blood serum activity in 3 months old animals by 33\% compared to control. In old animals there is no significant changes in GPx (Figure 4).

Consequently, the specificity of the changes of GPx activity in mitochondria and serum was different at CFR. Therefore the activity of different classes of GPx changes in different way in the response to CFR. Between young and old animals there were quantitative differences in GPx activity.

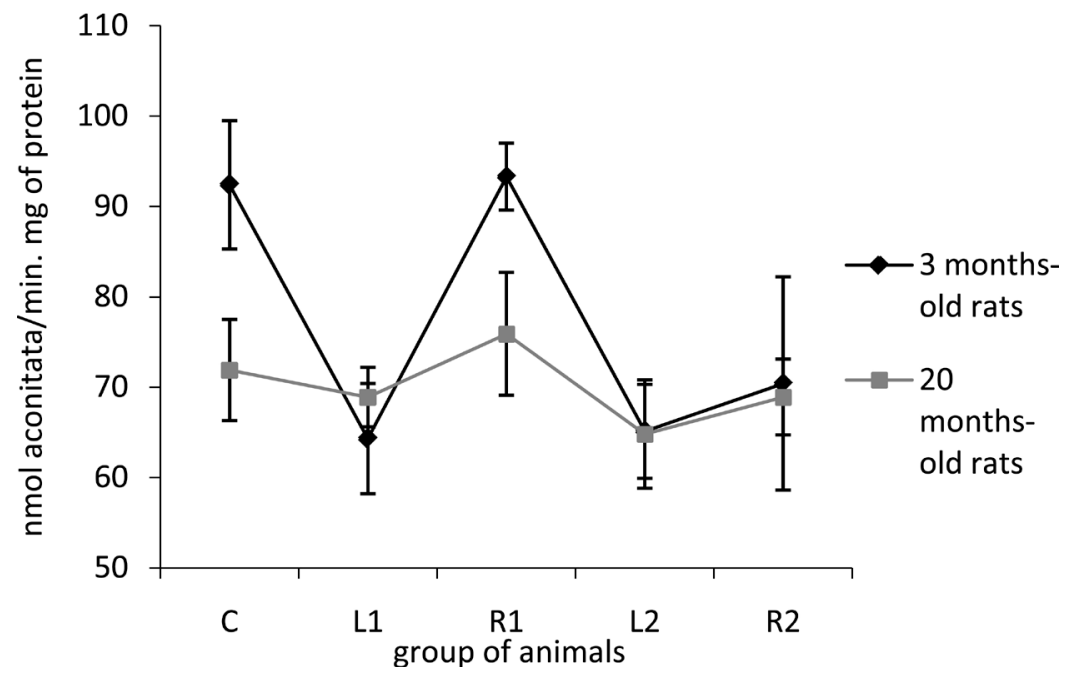

Figure 3. Activity of a conitase in young (3 months old) and old (20 months old) animals. C, L1, R1, L2, and R2-animal groups as in Figure 1. 

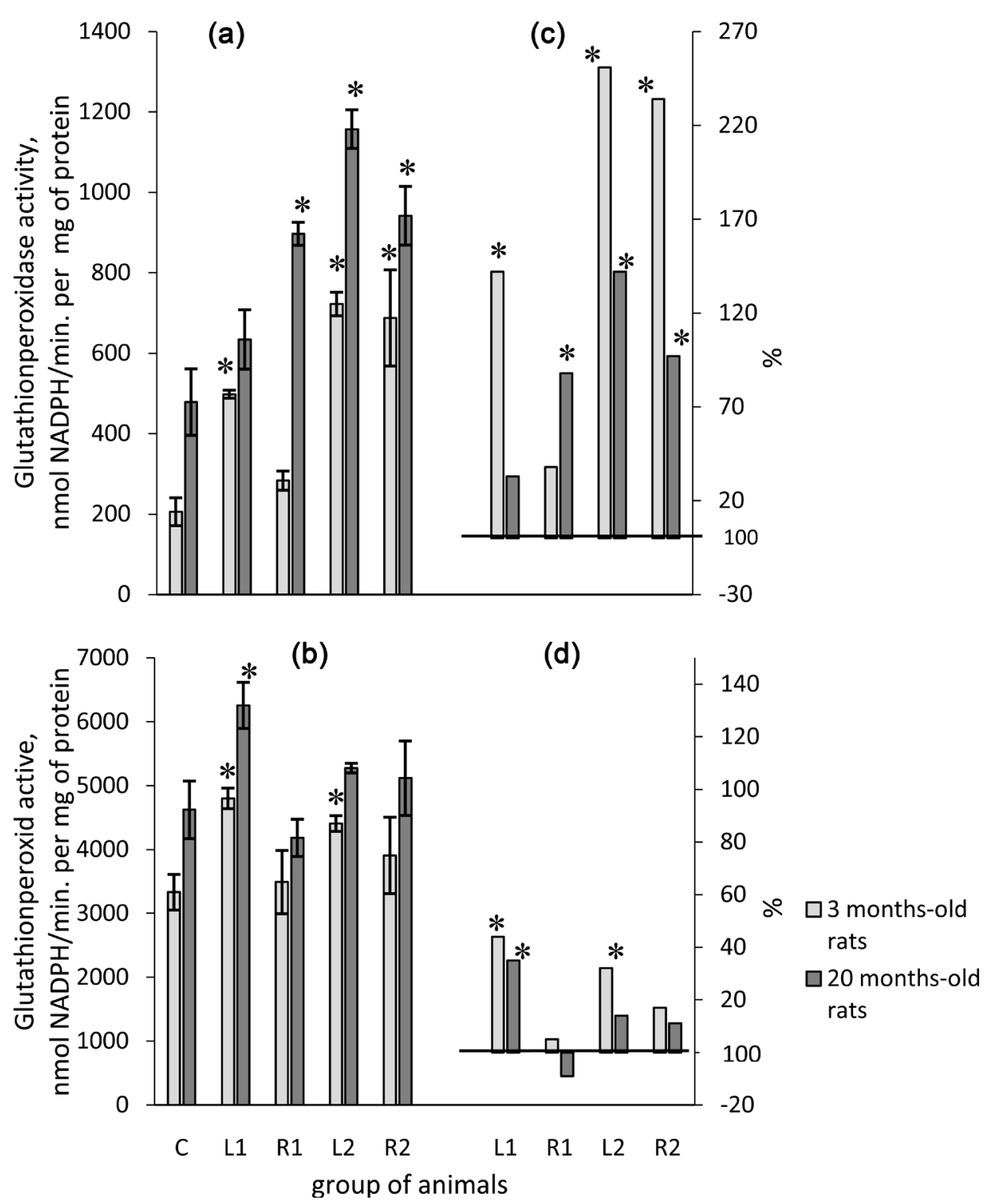

Figure 4. Activity of glutation peroxidase (nmol NADFH/ $\mathrm{min}$ on $\mathrm{mg}$ of protein) inthemitochondria (a) andserum blood (b) in young ( 3 months old) and old (20 months old) animals. C, L1, R1, L2, and R2-animal groups as in Figure 1. Changing of these parameters is shown in percent to the control level in mitochondria (c) and microsomes (d).

\subsection{Indexes of Cellular Immunity}

CFR has no or slight effect on cell immunity, in contrast to the reaction of cell pro/ antioxidant system.

The phagocytic index (PI), that reflects the number of bacteria ingested by white blood cells, after the first cycle of body mass loss not changes in young rats, and in 20 months old rats it increased in the second cycle of CFR (Figure 5).

The starving-ad libitum nutrition the CFR had no effect on PI in 3 months old rats. At the same time, this indicator slightly increased in the second cycle in old rats (Figure 5). The phagocytic number (absorption ability of white blood cells) also 
changed a little and remained close to control values in young and old rats (Table 1). The index of completion of phagocytosis was stable at CFR (Table 1).

As it is known, neutrophils phagocyte the damaged cells of the organism, secrete bactericidal substances, participate in the regeneration of damaged tissues and help the regeneration of damaged tissue [22]. Laboratory test with nitroblue tetrazolium (NBTtest) characterizes of $\mathrm{HADFH}-$ oxidase system of neutrophils. We assessed the spontaneous level (without induction) and induced by zymosan level of neutrophil oxidase system to evaluate the potential activity of oxidase system in neutrophils [23].

In the first cycle of body mass loss, spontaneous level of activity of oxidase system in neutrophils increased in 2.5 times to compared with control in young animals and in 1.9 times in old ones (Figure 6). After first cycle of body mass recovery the spontaneous level of activity of oxidase system in neutrophils in young animals increased in 4 times as compared with control and didn't change of old animals (Figure 6).

The second cycle of starving-ad libitum nutrition of CFR the spontaneous level activity of oxidase system in neutrophils of young animals was increased in 2.5 times as compared with control. In the old animals after the first cycle of recovery of body mass

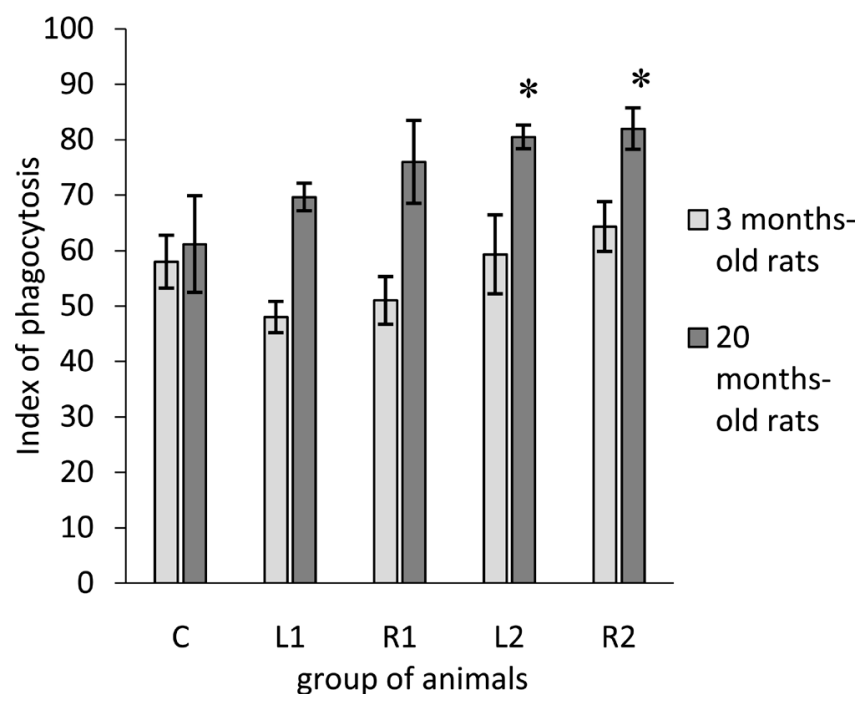

Figure 5. Indexes of phagocytosis in young ( 3 months old) and old ( 20 months old) animals. C, L1, R1, L2, and R2-animal groups as in Figure 1.

Table 1. Indicators of phagocytosis after cyclic feeding regime of young and old rats.

\begin{tabular}{llllll}
\hline \multirow{2}{*}{ Indicator of phagocytosis } & \multicolumn{4}{l}{ Animals group } & \multicolumn{2}{l}{ L2 } & $\mathrm{R} 2$ \\
\cline { 2 - 6 } & $\mathrm{C}$ & $\mathrm{L} 1$ & $\mathrm{R} 1$ & $\mathrm{~L} 2.15 \pm 0.07$ & $2.26 \pm 0.06$ \\
\hline PN 3 months old & $2.76 \pm 0.28$ & $2.56 \pm 0.13$ & $2.08 \pm 0.44$ & 2.15 \\
IPC 3 months old & $1.70 \pm 0.26$ & $1.71 \pm 0.09$ & $1.16 \pm 0.35$ & $1.24 \pm 0.02$ & $1.28 \pm 0.17$ \\
PN 20 months old & $2.03 \pm 0.10$ & $2.37 \pm 0.23$ & $2.77 \pm 0.51$ & $2.60 \pm 0.14$ & $2.36 \pm 0.08$ \\
IPC 20 months old & $1.25 \pm 0.09$ & $1.31 \pm 0.04$ & $1.50 \pm 0.31$ & $1.48 \pm 0.11$ & $1.54 \pm 0.16$ \\
\hline
\end{tabular}

$\mathrm{C}$-control group; L1 - the loss of body mass in the first cycle of CFR; R1-the restoration of body mass in the first cycle and, L2 and R2, respectively, in the second CFR cycle. 
(a)

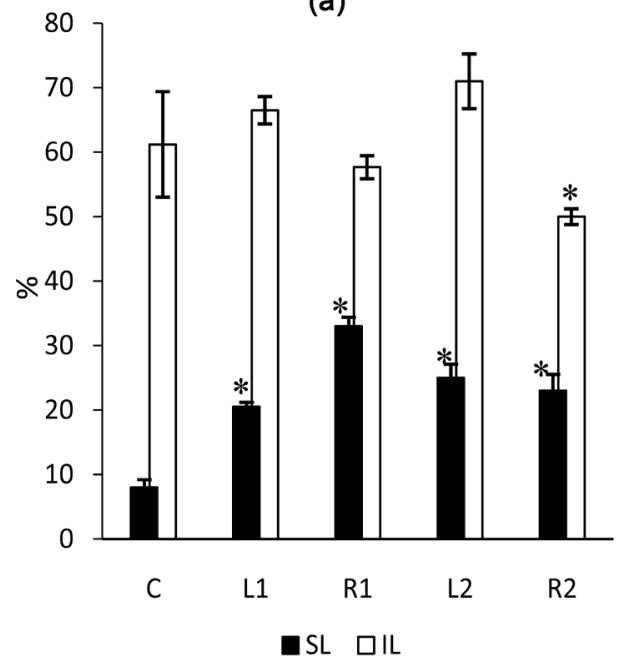

(b)

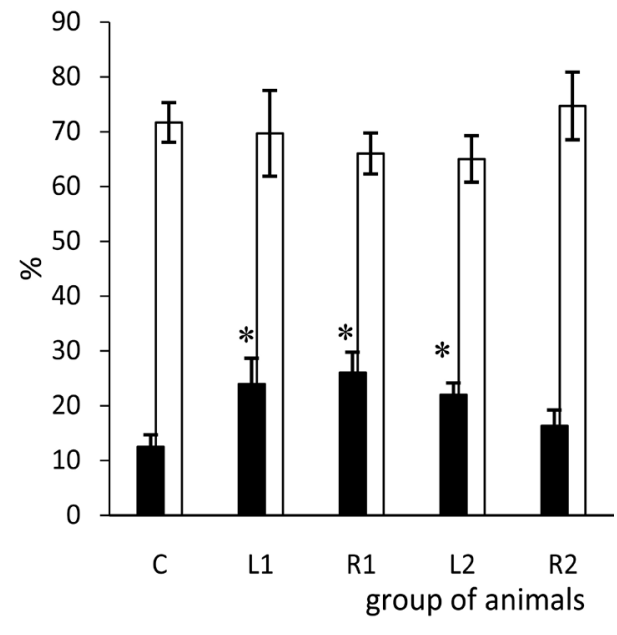

Figure 6. The number of neutrophils positively stained by diformazan (product of NBT oxidation) assessed in in vivo (spontaneous level, SL) and the number of neutrophils positively stained by diformazan after neutrophils stimulated by zymosan in vitro (induced level, IL). (a) Young and (b) old animals. C, L1, R1, L2, and R2-animal groups as in Figure 1.

of spontaneous level of activity of oxidase system in neutrophils didn't change from control group (Figure 6).

Therefore, activity of oxidase system in neutrophils reacted on CFR more in young than in old animals. The evidence of this is our data on the activity of this system after activation by zymosan in vitro.

It was shown than in control group of animals in neutrophils zymosan increased activity of oxidase system in 7.6 times in young animals as compared to spontaneous level in control; and it was increased in 5.7 times in old animals (Figure 6).

In case of starving-ad libitum nutrition during CFR the effect of stimulation of neutrophils by zymosan was more manifested in young animals (Figure 6). Therefore, applying of CFR is accompanied by the activation of the oxidase system in neutrophils in young and old animals, while a potential of increase of enzymatic activity of oxidase system remained high.

\section{Discussion}

The recognition of fact that nutrients are able to modulate the functions of organism has caused a revolution in the field of feeding [24]. At present, we know that a deficiency or excess of nutrients generates a specific epigenotype and affects life span [25] [26] [27]. In addition, components of nutrition act as antigens, mitogens and allergens and affect spontaneous and local immune response [28] [29].

Consequently, the food forms the field in that the metabolic system functions. However, along with qualitative and quantitative composition of food the features of metabolism are determined also by temporal characteristics of food ingestion or a feeding regime.

The formation of stable pattern of metabolism is due to two fundamental features of 
the metabolic systems organization: 1) cyclic character of processes based on the short "life" of the molecules; 2) availability of alternative metabolic pathways that provide the ability to adapt metabolism quickly and to maintain its integrity using various strategies enabling fast remodeling of metabolism. This explains the lack of "hard" cause-effect relationships in biological systems, in contrast to physical systems.

Unfortunately, the temporal organization of metabolism isn't studied enough, and this is due to the complexity of the study of nonlinear dynamic processes, and as a consequence to the lack of appropriate animal models. We believe that a model of CFR can serve as useful model for the studies not only of gerontology, but also in biology in general. Overall, the results of the present study revealed a number of new facts:

1) Variability in body mass, liver mass and indices of pro-oxidant system in response to the CFR in old animals were less pronounced than in young, i.e. the adaptive response was age-dependent.

2) Transfer of both young and old animals to the CFR, which was accompanied by a loss of body mass $(26 \%-30 \%)$ and liver mass $(31 \%-36 \%)$ was accompanied by a manifestation of oxidative stress accompanying the activation of the GPx, particularly pronounced in the first body mass loss in CFR, while characteristics of cellular immunity remained stable.

3) The response of metabolic and physiological systems to the CFR differed between the initial impact of CFR and subsequent cycles of CFR i.e. organism changed adaptation strategy by repeated influences the same factors that indicate: a) the shift of adaptive strategy and b) the formation of metabolic memory which modifies the adaptive processes and affects the choice of strategy for subsequent adaptations.

Since the body mass loss and its restoration are determined by the balance between lipid hydrolysis, lipid synthesis and accumulation of proteins and carbohydrates, the various strategies of body mass maintaining can be realized by successive periods of starving and ad libitum nutrition in course of CFR.

As it is known body mass loss may be due to physiological or pathological reasons. The decrease in body mass due to food restriction and diet change may be attributed to normal physiological mechanisms of body mass loss.

In CFR at the first cycle of mass loss, young and old animals lost almost about $30 \%$ in the 14 days of regime of starving. If the body mass loss accounted more than $40 \%$, the most of the animals perished [8]. Although at the maintenance of animals on classic CR, from one-month age, the body mass loss can reach up to $60 \%$ [8].

In that case, the young animals in the first cycle of CRF lost $30 \%$ of body mass, in the second cycle they could lose $35 \%$ - $40 \%$ under the same conditions without life threatening. Moreover, it has been shown previously that these animals have an increased lifespan [8]. In 20 months old rats at the same CFR regime the body mass, on the contrary, remained unchanged in the first 2 cycles, and at 3rd cycle, body mass decreased from $26 \%$ to $9 \%$ as it was previously shown [8]. Such difference in the periodic mass loss in young and old animals may indicate the intense catabolism in young, unlike the older animals. 
Large amount of glycogen and fat in old animals provides relative "protection" of the protein catabolism. It is suggested by a smaller loss of liver mass compared to the young in the first cycle of CFR. In the second cycle young animals lost $46 \%$ of liver mass, while in older it has not changed (Figure 1).

As it is known, the mass of muscle protein accounts for more than half of the body mass and in the case of physiological mass loss catabolism undergo primarily muscle proteins [30]. In our opinion, as the adult animals have more carbohydrate and fat depots, they largely retains its muscle mass under the same CFR conditions. Or, in other words, the young and old animals use different strategies to adapt to starving.

Naturally, in periods of body mass loss occurs not only catabolism of carbohydrates, lipids and proteins, but there is active synthesis of essential macromolecules that eventually accompanied by new metabolic patterns formation. It is believed that metabolic patterns formed in response to the CFR will provide the minimization of losses in subsequent cycles of insufficient nutrition.

The change of pro- and antioxidant indexes supports this conclusion in two ways:

1) The amount of lipid hydroperoxide species in liver mitochondria of old control animals did not exceed those of young animals, and the activity of GPx in the old was 2 times higher than in young animals. The GPx activity in the blood serum of the old group of animals also was significantly higher than in young animals. Such age changes in GPx activity result in decrease of amount of $\mathrm{LOOH}$ in microsomes of old animals (Figure 2, Figure 4).

The lower level of peroxidation in aged animals (control) is accompanied by lower activity of mitochondrial aconitase in old animals as compared to young (Figure 3).

These results do not agree with the statement that $\mathrm{LOOH}$ increase with age.

2) Amount of $\mathrm{LOOH}$ in liver mitochondria of young animals in response to a first cycle of body mass loss significantly increased, and to a greater extent than in older animals. At the same time amount of $\mathrm{LOOH}$ in microsomes of the old increased largely (Figure 2). In old animals the activity of the GPx in the mitochondria and blood serum increased to a less degree. However, the GPx activity remained significantly above the reference level and after CFR. It should be noted that the old animals at CFR diet have greater lifespan [8].

These results indicate that the loss of body mass in young and old animals to $30 \%$ during 14 days induces oxidative stress manifesting in high GPx activity, one of the key enzymes of glutathione cycle. This oxidative stress has been "formed" in young and old animals from various elements of prooxidant system. This can be explained by the presence of various carbohydrate and fat depots in young and old animals, as well as they have different metabolic memory.

It is important to note "decaying" nature of the response of prooxidant systems at the repeated cycles of CFR. This may indicate a change in strategy of adaptive responses.

A significant increase in the activity of the GPx at CFR that accompanies oxidative stress can be explained by the fact that the reactive oxygen species increase the gene expression of antioxidant enzymes [31]. 
It is known that increased production of hydrogen peroxide is an important regulatory factor. For instance, at pregnancy there is a pronounced manifestation of oxidative stress [32] and it was shown that $\mathrm{H}_{2} \mathrm{O}_{2}$ stimulates vasodilation on the background of GPx activation [33].

Oxidative stress provides activation of cellular immunity [34]. It is shown that activated by oxidative stress monocytes (macrophages) produce neopterin [35]. In 1967 Sakurai and Goto isolated neopterin from human urine and showed that its concentration increased by several orders in cancer patients [36]. At present is shown, that compounds with the pteridine structure are often found in biological systems and play an important role in immune cells self-protection from oxidative burst [37].

Results of this investigation suggest that a relatively stable level of activity of the cellular component of the immune defense that accompanies body mass loss may be associated with a relatively high cyclic changing of LOOH amount at a high activity of GPx.

It is known that starving, accompanied by a decrease of body mass, inhibits the activity of the immune system and in particular the cell-mediated immunity [38].

We believe that the CFR induces the formation of specific metabolic patterns, which provide the formation and maintenance of a specific adaptive epigenotype, and they are associated with greater lifespan.

Increased lifespan of animals which underwent 3 cycles of CFR [8] can be explained by three effects: effect of selection of most resistant to various stresses animals, by hormesis effect, and by formation of metabolic memory [39].

\section{References}

[1] McCay, C.M., Crowell, M.F. and Maynard, L.A. (1935) The Effect of Retarded Growth upon the Length of the Life Span and upon the Ultimate Body Size. Journal of Nutrition, 10, 63-79.

[2] Cava, E. and Fontana, L. (2013) Will Calorie Restriction Work in Humans? Aging (Albany NY), 5, 507-514. http://dx.doi.org/10.18632/aging.100581

[3] Masoro, E.J. (2005) Overview of Caloric Restriction and Ageing. Mechanisms of Ageing and Development, 126, 913-922. http://dx.doi.org/10.1016/j.mad.2005.03.012

[4] Speakman, J.R., Mitchell, S.E. and Mazidi, M. (2016) Calories or Protein? The Effect of Dietary Restriction on Lifespan in Rodents Is Explained by Calories Alone. Experimental Gerontology, in Press. http://dx.doi.org/10.1016/j.exger.2016.03.011

[5] Gilmore, L.A., Ravussin, E. and Redman, L.M. (2015) Anti-Aging Effects of Nutritional Modification: The State of the Science on Calorie Restriction. Book Handbook of Clinical Nutrition and Aging, IV, 315-334. http://dx.doi.org/10.1007/978-1-4939-1929-1_20

[6] Yu, B.P. (1996) Aging and Oxidative Stress: Modulation by Dietary Restriction. Free Radical Biology \& Medicine, 21, 651-668. http://dx.doi.org/10.1016/0891-5849(96)00162-1

[7] Bozhkov, A.I. and Nikitchenko, Yu.V. (2013) Caloric Restriction Diet Induced Specific Epigenotypes Associated with Life Span Extension. Journal of Nutritional Therapeutics, 2, 30-39.

[8] Bozhkov, A.I., Kurguzova, N.I., Krivoruchko, T.V., Lebed', E.N., Mikhailets, A.O., Danladi, S.D., Bozhkov, A.A. and Girich, M.S. (2014) A Cyclic Feeding Regime: A New Modelin Experimental Gerontology. Advances in Gerontology, 4, 251-257.

http://dx.doi.org/10.1134/S2079057014040079 
[9] Girych, M.S., Kurguzova, N.I. and Bozhkov, A.I. (2015) Cyclic Intermittent Fasting Influences the Structure of Hepatocyte Nuclear Memrane in Young and Old Rats. Journal of Advances in Biology \& Biotechnology, 2, 38-50.

http://dx.doi.org/10.9734/JABB/2015/13771

[10] Paglia, D.E. and Valentine, W.N. (1967) Studies on the Quantitative and Qualitative Characterization of Erythrocyte Glutathione Peroxidase. Journal of Laboratory and Clinical Medicine, 70, 158-169.

[11] Muniz-Junqueira, M.I., Peçanha, L.M., Silva-Filho, V.L., de Almeida Cordoso, M.C. and Tosta, C.E. (2003) Novel Microtechnique for Assessment of Postnatal Maturation of the Phagocytic Function of Neutrophils and Monocytes. Clinical and Diagnostic Laboratory Immunology, 10, 1096-1102. http://dx.doi.org/10.1128/cdli.10.6.1096-1102.2003

[12] Freeman, R. and King, B. (1972) Technique for the Performance of the Nitro-Blue Tetrazolium (NBT) Test. Journal of Clinical Pathology, 25, 912-914. http://dx.doi.org/10.1136/jcp.25.10.912

[13] Kamatch, S.A. and Narayan, K.A. (1972) Interaction of $\mathrm{Ca}^{2+}$ with Endoplasmic Reticulum of Rat Liver: A Standard Procedure for the Isolation of Microsomes. Analytical Biochemistry, 48, 53-61. http://dx.doi.org/10.1016/0003-2697(72)90169-8

[14] Ohkawa, H., Ohahi, N. and Jadi, K. (1979) Assay for Lipid Peroxides in Animal Tissues by Thiobarbituric Acid Reaction. Analytical Biochemistry, 95, 351-358. http://dx.doi.org/10.1016/0003-2697(79)90738-3

[15] Varghese, S., Tang, Y. and Imlay, J.A. (2003) Contrasting Sensitivities of Escherichia coli Aconitases A and B to Oxidation and Iron Depletion. Journal of Bacteriology, 185, 221-230. http://dx.doi.org/10.1128/JB.185.1.221-230.2003

[16] Glantz, S. (1996) Primer of Biostatistics. McGraw Hill, New York.

[17] Gardner, P.R., Nguyen, D.D. and White, C.W. (1994) Aconitase Is a Sensitive and Critical Target of Oxygen Poisoning in Cultured Mammalian Cells and in Rats Lungs. Proceedings of the National Academy of Sciences, 91, 12248-12252. http://dx.doi.org/10.1073/pnas.91.25.12248

[18] Andersson, U., Leighton, B., Young, M.E., Blomstrand, E. and Newsholme, E.A. (1998) Inactivation of Aconitase and Oxoglutarate Dehydrogenase in Skeletal Muscle in Vitro by Superoxide Anions and/or Nitric Oxide. Biochemical and Biophysical Research Communications, 249, 512-516. http://dx.doi.org/10.1006/bbrc.1998.9171

[19] Li, Q.Y., Pedersen, C., Day, B.J. and Patel, M. (2001) Dependence of Excitotoxic Neurodegeneration on Mitochondrial Aconitase Inactivation. Journal of Neurochemistry, 78, 746755. http://dx.doi.org/10.1046/j.1471-4159.2001.00457.x

[20] Branco, V., Canário, J., Lu, J., Holmgren, A. and Carvalho, C. (2012) Mercury and Selenium Interaction in Vivo: Effects on Thioredoxin Reductase and Glutathione Peroxidase. Free Radical Biology \& Medicine, 52, 781-793. http://dx.doi.org/10.1016/j.freeradbiomed.2011.12.002

[21] Flohé, R.B. and Maiorino, M. (2013) Glutathione Peroxidases. Biochimica et Biophysica Acta, 1830, 3289-3303. http://dx.doi.org/10.1016/j.bbagen.2012.11.020

[22] Cowland, J.B. and Borregaard, N. (2016) Granulopoiesis and Granules of Human Neutrophils. Immunologival Reviews, 273, 11-28. http://dx.doi.org/10.1111/imr.12440

[23] Almeidaa, B.F.M., Narcisoa, L.G., Boscoa, A.M., Pereiraa, P.P., Bragaa, E.T., Avançoa, S.V., Marcondesb, M. and Ciarlinib, P.C. (2013) Neutrophil Dysfunction Varies with the Stage of Canine Visceral Leishmaniosis. Veterinary Parasitology, 196, 6-12. http://dx.doi.org/10.1016/j.vetpar.2013.02.016 
[24] Shrimpton, D.H. (2004) Nutritional Implications of Micronutrients Interactions. Chemist and Druggist, $15,38-41$.

[25] Kurguzova, N.I., Bozhkov, A.I., Nikitchenko, Y.V., Al Begai, M.A.Y., Goltvyansky, A.V., Alsardia, M.M.A. and Bozhkov, A.A. (2015) Interconnection of Antitoxic and Antioxidant Systems of the Organism under the Action of Natural Low Molecular Complex-Fungidol. American Journal of Biomedical and Life Sciences, 2, 25-32.

[26] Bozhkov, A.I., Nikitchenko, Y.V., Sheremet, A.A. and Bozhkov, A.A. (2014) The Prooxidant-Antioxidant System Is the Primary Stage of the Answer of Organism on Unbalanced Diet. Journal of Harmonized Research in Pharmacy, 3, 78-90.

[27] Bozhkov, A.I. and Nikitchenko, Y.V. (2014) Thermogenesis and Longevity in Mammals. Thyroxin Model of Accelerated Aging. Experimental Gerontology, 60, 173-182. http://dx.doi.org/10.1016/j.exger.2014.10.017

[28] Calder, P.C. and Yaqoob, P. (2012) Nutrient Regulation of the Immune Response. In: Erdman Jr., J.W., MacDonald, I.A. and Zeisel, S.H., Eds., Present Knowledge in Nutrition, 10th Edition, John Wiley \& Sons, Hoboken, 688-708. http://dx.doi.org/10.1002/9781119946045.ch44

[29] Menshikova, E.A. (2015) The Influence of Nutrition on Immune Response of People in the North. Ekologiya cheloveka [Human Ecology], 12, 10-15.

[30] Thompson, L.V. (2009) Age-Related Muscle Dysfunction. Experimental Gerontology, 44, 106-111. http://dx.doi.org/10.1016/j.exger.2008.05.003

[31] Birben, E., Sahiner, U.M., Sackesen, C., Erzurum, S. and Kalayci, O. (2012) Oxidative Stress and Antioxidant Defense. Cellular Signalling, 24, 981-990. http://dx.doi.org/10.1097/wox.0b013e3182439613

[32] Duhig, K., Chappell, L.C. and Shennan, A.H. (2016) Oxidative Stress in Pregnancy and Reproduction. Obstetric Medicine, 9, 113-116. http://dx.doi.org/10.1177/1753495X16648495

[33] Moreno, J.M., Gomez, I.R., Wangensteen, R., Perez-Abud, R., Duarte, J., Osuna, A. and Vargas, F. (2010) Mechanisms of Hydrogen Peroxide-Induced Vasoconstriction in the Isolated Perfused Rat Kidney. Journal of Physiology and Pharmacology, 61, 325-332.

[34] Nathan, C. and Cunningham-Bussel, A. (2013) Beyond Oxidative Stress: An Immunologist's Guide to Reactive Oxygen Species. Nature Reviews Immunology, 13, 349-361. http://dx.doi.org/10.1038/nri3423

[35] Mangge, H., Becker, K., Dietmar, F. and Gostner, J.M. (2014) Antioxidants, Inflammation and Cardiovascular Disease. World Journal of Cardiology, 6, 1-16. http://dx.doi.org/10.4330/wjc.v6.i6.462

[36] Sakurai, A. and Goto, M. (1967) Neopterin: Isolation from Human Urine. Journal of Biochemistry, 61, 142-145.

[37] Tomšíková, H., Tomšík, P., Solich, P. and Nováková, L. (2013) Determination of Pteridines in Biological Samples with an Emphasis on Their Stability. Bioanalysis, 5, 2307-2326. http://dx.doi.org/10.4155/bio.13.194

[38] Filippova, O.E., Popovski, Y.V., Shashkovo, E.Y. and Shchegoleva, L.S. (2016) Activity Lymphoid Lymphoproliferation and Apoptosis Receptors in the Physiological Regulation of Immune Homeostasis in Human Adaptation to Changing Environmental Conditions. Life Sciences, 1, 87-99. (In Russian)

[39] Bozhkov, A.I., Sidorov, V.I., Kurguzova, N.I. and Dlubovskaya, V.L. (2014) Metabolic Memory Enhances the Effect of Hormesis to Copper Ions and Has a Character of Age. Uspekhy Gerantologii, 27, 72-80. (In Russian) 
Submit or recommend next manuscript to SCIRP and we will provide best service for you:

Accepting pre-submission inquiries through Email, Facebook, LinkedIn, Twitter, etc. A wide selection of journals (inclusive of 9 subjects, more than 200 journals)

Providing 24-hour high-quality service

User-friendly online submission system

Fair and swift peer-review system

Efficient typesetting and proofreading procedure

Display of the result of downloads and visits, as well as the number of cited articles

Maximum dissemination of your research work

Submit your manuscript at: http://papersubmission.scirp.org/

Or contact aar@scirp.org 